Proceedings

\title{
Innovative Strategies in the Educational Field: Analysis of the Systematic Mapping of Literature ${ }^{\dagger}$
}

\author{
Leticia Nayeli Ramírez-Ramírez * and María Soledad Ramírez-Montoya * \\ Escuela de Humanidades y Educación, Tecnológico de Monterrey, 64849 Monterrey, Mexico \\ * Correspondence: leticia.rmrz@itesm.mx (L.N.R.-R.), solramirez@itesm.mx (M.S.R.-M.) \\ + Presented at the 2nd Innovative and Creative Education and Teaching International Conference \\ (ICETIC2018), Badajoz, Spain, 20-22 June 2018.
}

Published: 26 October 2018

\begin{abstract}
Educational innovation appears as a pending issue in the agendas of educational institutions at the international level. Current educational policies highlight the importance of educational innovation as a key element for improving educational quality and social development. From a sociocultural perspective, the social and situated character of innovation is highlighted as a process that takes place through multidisciplinary interaction and involves collaboration networks between different educational agents, institutions, and users. Through a systematic mapping of the literature, the research produced at international level on innovative strategies used in education was identified and characterized.
\end{abstract}

Keywords: innovative strategies; sociocultural; systematic mapping of literature

\section{Introduction}

Innovation is outlined as a pillar in promoting the educational transformations necessary for the improvement of educational quality and social development, such changes can occur at the macro level (e.g., policies of the education system, organization of the school institution) as well as at the micro level (dynamics of the educational community, student-teacher interaction). The key role that educational innovation plays in the development and improvement of teaching-learning processes, the innovative behavior of individuals, organizations, and economies, however, has been little explored in the educational literature [1-3], on the characteristics and typology of the educational innovations produced in the different social contexts, as well as the scope and impact that these innovations have for the agents of the educational process.

\section{Theoretical Framework}

Innovation is a polysemy concept, in this work it is glimpsed from a socio-cultural perspective [3] as a situated social process that does not occur in isolation and rather happens through multidisciplinary interaction involving collaboration networks between different educational agents, institutions and users, such as: teachers, students, parents, administrators, businessmen and managers. Thus, educational centers such as universities, colleges, and baccalaureates are central nodes in which innovation processes occur [4] and act as a flexible bridge to be linked in a triple helix; educational centers-companies-governments. The central role of universities in the innovative company and its relationship with business sectors has been widely recognized [5]. Following the current categories proposed by the OECD [6], educational innovation can be placed in four dimensions, namely: (1) new products or services, such as a new syllabus, textbooks or educational resources; (2) new processes to deliver their services such as the use of e-learning platforms; (3) new 
ways of organizing your activities, e.g., Ways to organize communication with students or parents and (4) new marketing techniques, for example, sales strategies or offers for graduate courses.

\section{Method}

A systematic mapping of the literature was carried out [7-9], whose main objective is the classification and management of a thematic analysis to identify trends in a research topic. In such a way, that a "map" is provided on the different categories generated and their relationship with the number of publications found through a systematic search. The present investigation was carried out through three phases (see Figure 1). In this phase, research questions, keywords, and search strategies were defined in the databases. As suggested by Petersen [7] in the systematic mapping the questions must reach two objectives; identify the quantity and type of research produced in the area (R1, R2, R3) and the lines, themes, forums in which these investigations have been published (R4, R5, R6). Subsequently, a systematic search was launched in two databases SCOPUS and Web of Science (WOS), the choice of these bases was related to the quality and prestige of the publications contained therein and the international coverage they present. In both cases, similar search criteria were maintained, with the following inclusion criteria: (a) Combination of keywords: "innovation strategy" and "education", (b) Type of documents: Articles, (c) Years of publication: 2013-2017 range, (d) Discipline: Social sciences or education. We excluded publications that: (a) corresponded to the type of document: conferences, book reviews, book chapters, (b) range of years before 2013 and (c) that belonged to other disciplinary areas other than the social sciences or education.

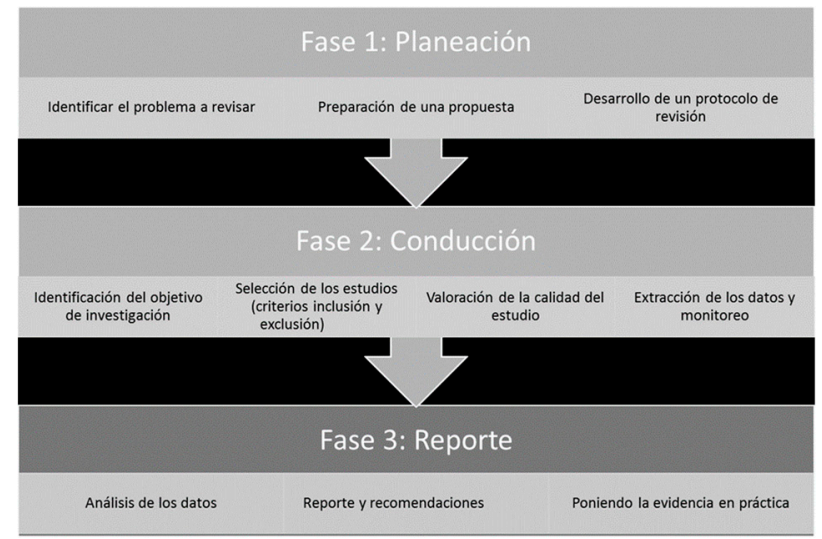

Figure 1. Phases of systematic literature mapping (modified with information from Tranfield, Denyer \& Smart, 2003).

\section{Results}

\subsection{Research on Innovative Strategies in the Educational Field}

In the characterization of the researches collected on the theme of Innovative Strategies, it was found that of the total sample identified $(\mathrm{N}=43)$, the country with the highest frequency of publication is the United States (5), followed by Spain (4), United Kingdom (3), China (3), Australia (3), Africa (2), Denmark (2), Malaysia (2), Taiwan (2), Slovenia (2), and Turkey (2). On the other hand, the lowest publication frequency (1) is presented in South Africa, Germany, Canada, Chile, Finland, Holland, Hong Kong, Malta, Norway, Poland, Sweden, Switzerland, Taiwan and Tunisia. In Figure 2, the map mapped in Tableau $\odot$ is presented with the geographical location of the countries in which the subject is published and the frequency represented in the size of the circles that place those countries on the map. In Figure 3, the complete data of the scientific journals and the distribution of their publication frequency per year are shown. 


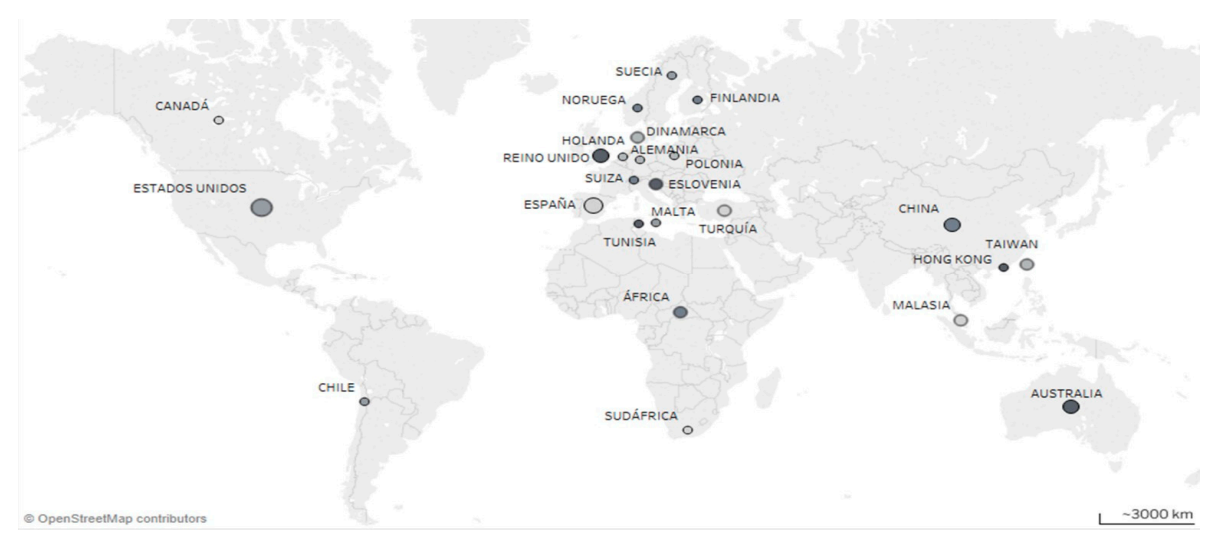

Figure 2. Geographic location and frequency of publication on the research topic. Own elaboration.

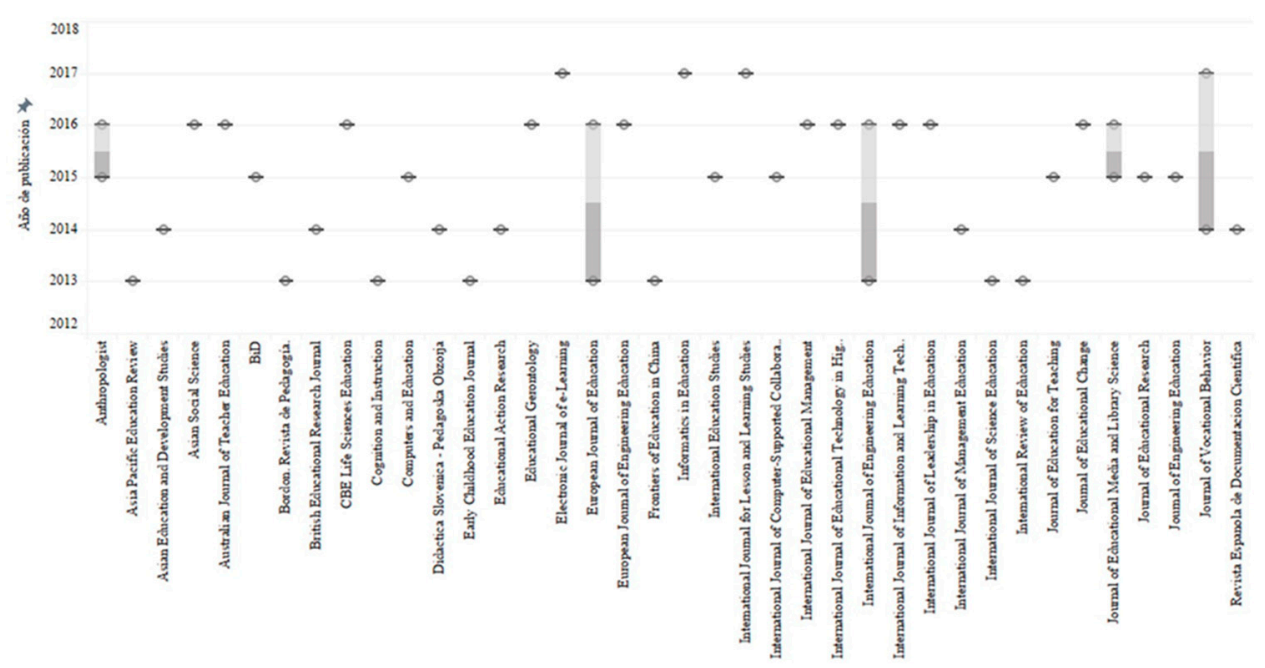

Figure 3. Distribution of the frequency of publication in the subject by year and scientific magazine. Own elaboration.

\subsection{Social Contexts of Innovative Strategies: Educational Organizations, Companies, and Hospitals}

Based on the research identified, three social contexts emerged in which production can be placed on innovative strategies. These contexts are mainly educational organizations (37 of the articles were placed in this context), companies (5) and hospitals (1). The target populations of the investigations are diverse; students (14), professors (13), administrative (7), workers (3), librarians (2) and researchers (1). The relationship between social contexts and populations located in the researchers analyzed is shown in Figure 4.

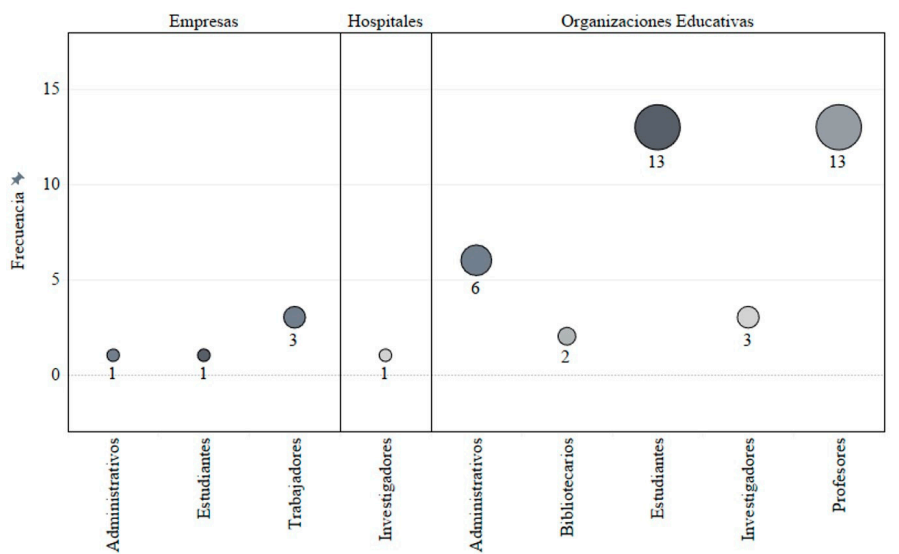

Figure 4. Social contexts and populations that have been addressed in the investigations of the subject. Own elaboration. 


\subsection{Types of Studies and Innovation Carried Out in Research}

In a general way, we find, in the analyzed literature, that most of the research production is concentrated in empirical studies (36), followed by systematic reviews of the literature (4) and finally theoretical articles (3). Within these types of studies, we identify the type of educational innovation addressed in the research (See Figure 5).

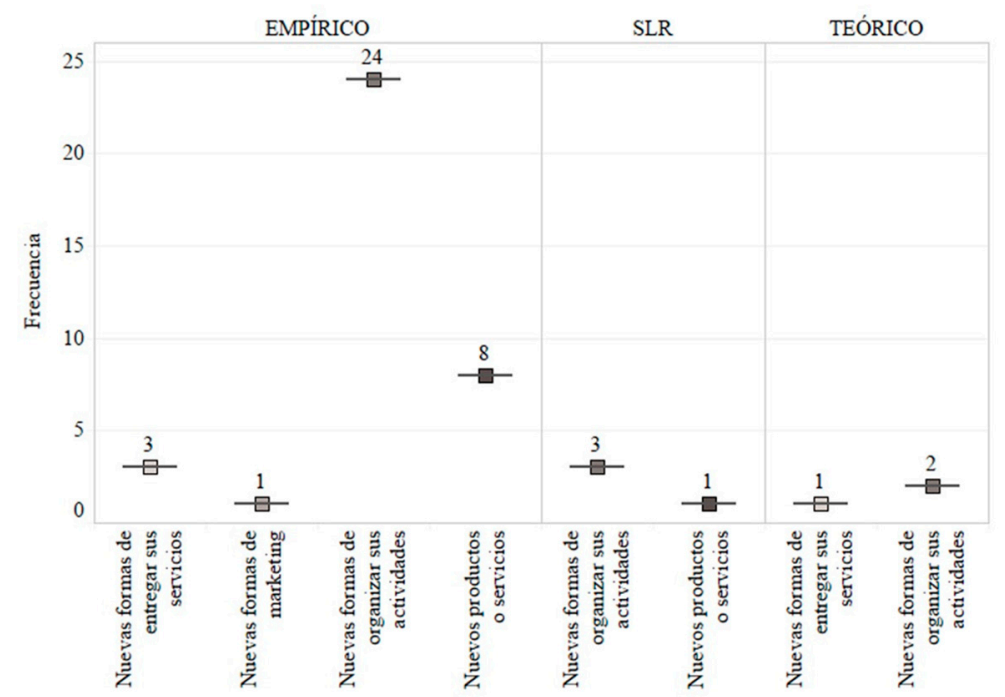

Figure 5. Type of innovation and studies identified in the systematic mapping of literature. Own elaboration.

\section{Discussion}

Based on the mapping of the literature, international research on innovative strategies in the field of education was identified and characterized. It was identified that the majority of countries that conduct research on the subject are concentrated in Europe; on the other hand, in South America, Africa and Oceania are still incipient research on the subject. Regarding the temporary distribution of publication, we identified an increasing trend in the publication that focuses on the year 2016. Also, it was found that, of the 38 journals with an educational focus, only five of them present a higher frequency of publication. Through these data, the research need that presents the theme of innovative strategies in the educational field is evident.

Supplementary Materials: The following are available online at: https:/drive.google.com/drive/folders/ 0BzVCn3NklcHBdU5ZLV9qd2d0Tk0?usp=sharing.

Author Contributions: The first author have the more important contribution in the planning, analysis of results and the written of manuscript. The second author contribute for the method and conclusions.

Acknowledgments: We appreciate the support provided by the Tecnológico de Monterrey for accessing the databases. This research is the product of project 266632 "Binational Laboratory for the Intelligent Management of Energy Sustainability and Technological Training" funded by CONACYT SENER fund for Energy Sustainability (Agreement: S0019201401).

Conflicts of Interest: The authors declare no conflict of interest.

\section{References}

1. Maritz, A.; De Waal, A.; Buse, S.; Herstatt, C.; Lassen, A.; Maclachlan, R. Innovation education programs: Toward a conceptual framework. Eur. J. Innov. Manag. 2014, 17, 166-182, doi:10.1108/EJIM-06-2013-0051.

2. Richmond, G.; Tatto, M.T. Innovation in Educational Research. J. Teach. Educ. 2016, 67, 360-362, doi:10.1177/0022487116670866.

3. Frane, A.; Westlund, H. Innovation in Socio-Cultural Context; Routledge: New York, NY, USA, 2013. 
4. OECD. The OECD Innovation Strategy: Getting a Head Start on Tomorrow; OECD Publishing: Paris, France, 2010.

5. Etzkowitz, H. Triple helix clusters: Boundary permeability at university-industry-government interfaces as a regional innovation strategy. Environ. Plan. C Gov. Policy 2012, 30, 766-779, doi:10.1068/c1182.

6. OECD. Innovating Education and Educating for Innovation: The Power of Digital Technologies and Skills; OECD Publishing: Paris, France, 2016, doi:10.1787/9789264265097-en.

7. Petersen, K.; Feldt, R.; Mujtaba, S.; Mattsson, M. Systematic Mapping Studies in Software Engineering. In Proceedings of the 10th International Conference on Evaluation and Assessment in Software Engineering, Keele, UK, 2-3 April 2007; pp. 1-10.

8. Tranfield, D.; Denyer, D.; Smart, P. Towards a Methodology for Developing Evidence-Informed Management Knowledge by Means of Systematic Review. Br. J. Manag. 2003, 14, 207-222.

9. Kitchenham, B.; Pretorius, R.; Budgen, D.; Brereton, O.P.; Turner, M.; Niaz, M.; Linkman, S. Systematic literature reviews in software engineering-A. tertiary study. Inf. Softw. Technol. 2010, 52, 792-805, doi:10.1016/j.infsof.2010.03.006.

(C) 2018 by the authors. Licensee MDPI, Basel, Switzerland. This article is an open access article distributed under the terms and conditions of the Creative Commons Attribution (CC BY) license (http://creativecommons.org/licenses/by/4.0/). 